OPEN ACCESS

Edited by: Pamela Bryden,

Wilfrid Laurier University, Canada

Reviewed by:

Ehsan Namaziandost,

Mehrarvand Institute of Technology,

Iran

Barbara A. Kerr,

University of Kansas, United States

*Correspondence:

Alaa Eldin A. Ayoub

alaaeldinaa@agu.edu.bh

Specialty section:

This article was submitted to

Cognition,

a section of the journal

Frontiers in Psychology

Received: 20 May 2021

Accepted: 16 December 2021

Published: 27 January 2022

Citation:

Ayoub AEA, Aljughaiman AM, Alabbasi AMA and Abo Hamza EG

(2022) Do Different Types

of Intelligence and Its Implicit Theories

Vary Based on Gender and Grade

Level? Front. Psychol. 12:712330.

doi: 10.3389/fpsyg.2021.712330

\section{Do Different Types of Intelligence and Its Implicit Theories Vary Based on Gender and Grade Level?}

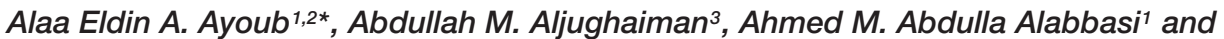 \\ Eid G. Abo Hamza ${ }^{4,5}$
}

${ }^{1}$ College of Graduate Studies, Arabian Gulf University, Manama, Bahrain, ${ }^{2}$ Department of Educational Psychology, Aswan University, Aswan, Egypt, ${ }^{3}$ Department of Special Education, King Faisal University, Al-Ahsa, Saudi Arabia, ${ }^{4}$ College of Humanities and Sciences, Ajman University, Ajman, United Arab Emirates, ${ }^{5}$ Faculty of Education, Tanta University, Tanta, Egypt

The current study investigated correlations among gifted students' academic performance; emotional, social, analytical, creative, and practical intelligence; and their implicit theories of intelligence. Furthermore, it studied the effect of gender and grade on these variables. The participants included 174 gifted fifth (41.4\%) and sixth (58.6\%) grade students, comprising 53.4\% male and $46.6 \%$ female. The following analytical, creative, and practical intelligence tests were administered: Aurora Battery, the emotional intelligence scale, the implicit theories of intelligence scale, and an assessment scale of students' performances. The results revealed significant correlations among academic performance, kinds of intelligence, and implicit theories of intelligence. There were no significant differences between the male and female students in these measures. There were, however, significant differences between the fifth and sixth grade students, with the sixth-grade students showing higher levels of all kinds of intelligence, except emotional intelligence. Moreover, the results indicated that the intelligence measures were non-significantly affected by either gender or gendergrade interaction. Overall, our results showed that most types of intelligence are related to giftedness, and that there were no gender differences among gifted students on measures of intelligence.

\footnotetext{
Keywords: intelligence, implicit theories of intelligence, types of intelligence, academic performance, gifted students, Aurora Battery
}

\section{INTRODUCTION}

The current article investigated the relationship between academic performance and the different kinds of intelligence in gifted students. It also investigates the impact of grade level and gender both on these different kinds of intelligence and academic performance. A multitude of studies have been conducted on intelligence in the context of educational psychology (Cantero et al., 2020; Sanchez-Alvarez et al., 2020). There are a wide range of views about the nature of intelligence, starting from the view that intelligence is fixed upon birth to the view that it is malleable and can be developed and changed depending on an individual's mindset and efforts (Deary, 2000; Haimovitz and Dweck, 2016). Furthermore, there are a wide range of opinions regarding how intelligence is related to other factors (Garlick, 2002; Maass et al., 2008; Johnson et al., 2010). Efforts have 
been devoted to find a correlation between traditional construct of general intelligence ( $g$ ) with the performance in school or in workplace. Some studies found that general intelligence might serve as a good predictor of achievement in schools and workplace (Schmidt and Hunter, 1998; Gottfredson, 2018), for example, there is enough research evidence that general intelligence ( $g$ factor) is a good predictor of achievement, with a correlation typically around 0.5-0.6 (Gustafsson and Undheim, 1996; Gottfredson, 2005). While there is wide acceptance of a good correlation between intelligence and achievement, the magnitude of the correlation has little consistency (Deary et al., 2007). However, meta-analysis studies found that intelligence may play as a powerful predictor of success, however, it is not the only one predictor as there are several other factors may serve better predictor than general intelligence (Grigorenko and Sternberg, 2001; Strenze, 2007; Credé et al., 2017).

More specifically, many studies spanning several decades have focused on studying different kinds of intelligence in gifted students (Worrell et al., 2019; Erden et al., 2020). For example, it has been shown that gifted students score higher on intelligence measures than non-gifted students (McClain and Pfeiffer, 2012); therefore, revealing that high intelligence may be a key contributing factor to high academic performance (Deary et al., 2007; Dutton et al., 2014; Gomes et al., 2014).

Some more recent studies have focused on the correlation between implicit theories of intelligence and academic performance (Blackwell et al., 2007; Chen and Wong, 2015; Claro et al., 2016; Martin et al., 2017), while others have focused on their correlation with several psychological factors, such as self-regulation (Burnette et al., 2013), self-efficacy (Chen and Tutwiler, 2017), self-esteem (Diseth et al., 2014), social judgments (Erdley and Dweck, 1993), and motivation (Hong et al., 1995; Renaud-Dubé et al., 2015). Overall, this approach usually focuses on the impact of holding different implicit theories (entity or incremental) about intelligence or other aspects, such as social skills, emotional skills, and achievement (Dweck, 2012).

We know from previous literature that an implicit theory of intelligence influences student achievement (Blackwell et al., 2007; Romero et al., 2014), but no conclusions have been reached regarding the positive or negative effects of incremental or entity beliefs (Costa and Faria, 2018).

The correlation between emotional intelligence and general intelligence was examined by several researchers. However, the outcomes of these studies have been quite inconsistent (Buşu, 2020). For instance, Martínez-Rubio et al. (2014) found that there is no direct relationship between emotional intelligence and general intelligence, while Lam and Kirby (2002) found that emotional intelligence explained individual, cognitivebased performance over and beyond the level attributable to general intelligence. Social intelligence has been overlapped with emotional intelligence. However, there is a clear distinction between the two concepts (Goleman, 2006), although they both are significantly related to each other (Grieve and Mahar, 2013). On another hand, the link between emotional intelligence and academic performance has also been the subject of research by a number of researchers, as many studies have indicated a positive relationship between them (Durlak et al., 2011; Perera and DiGiacomo, 2013). In a more recent meta-analysis study performed by MacCann et al. (2020) found that there is a small to moderate relationship between emotional intelligence and academic performance. One interesting finding of MacCann et al. (2020) study is that they found ability emotional intelligence test was a significantly stronger predictor than self-report.

Social and emotional intelligence are not fixed, and individuals are able to improve them through educational intervention (Mayer et al., 1999). Here again, there are no clear conclusions from previous research regarding positive or negative effects of incremental or entity beliefs on social or emotional intelligence (Romero et al., 2014).

On other hand, previous research studies have not reached a conclusion whether age and/or gender affect implicit theories about intelligence (Cabello and Fernández-Berrocal, 2015). In addition, few studies have attempted to explore the correlation between implicit theories of intelligence and several types of intelligence, as well as how they are affected by the age and gender of gifted students. Most of the scientific work on this matter focused on general intelligence. Therefore, this article is an attempt to contribute to the body of literature by exploring the correlation among some of the types of the intelligence and their implicit theories. In summary, this article attempts to answer the following questions: do performance, social, emotional, practical, creative, analytical intelligence, and implicit theories of intelligence form a network of interrelated variables? Do the correlations vary based on gender and/or grade level?

\section{Types of Intelligence}

Intelligence is a multidimensional construct that involves, to name a few, social, emotional, practical, and analytical intelligence (Ayoub and Aljughaiman, 2016; Gonzalez-Trevino et al., 2020; Yildiz et al., 2020). More than one hundred years ago, intelligence was believed to be a unitary construct (Spearman, 1904; Thorndike, 1920). However, over the last few decades, evidence-based research has shown that intelligence involves multiple different types and subcomponents (Cattell, 1963; Horn and Cattell, 1966; Mayer et al., 2001; Carroll, 2003; Flanagan and Harrison(eds), 2012). Importantly, some types of intelligence have received more attention within the field than others. In the following paragraphs, we will briefly introduce the different types of intelligences measured in this study.

Emotional intelligence is one's ability to understand and manage both their emotions and those of others (Zakariasen and Victoroff, 2012; Zeidner and Matthews, 2017; Matthews et al., 2018; O'Connor et al., 2019). Social intelligence is somewhat related to emotional intelligence. Unlike emotional intelligence, social intelligence refers to one's ability to understand and manage other people and to succeed in various social interactions (Thorndike and Stein, 1937). It has been argued that social intelligence involves emotional intelligence processes, as managing people involves understanding their emotional state. However, there has been a limited number of studies on the relationship between emotional and social intelligence in gifted students.

Ferrando et al. (2016) relied on Sternberg's definition of successful intelligence, in which it was described as one's ability 
to set and accomplish personally meaningful goals in one's life, given one's cultural context. Although intelligence is viewed as being of various kinds, the mental processes involved in creative, analytical, practical, and wise thinking are the same.

Successful intelligence is also defined as the ability to achieve success in life, given one's personal standards within their sociocultural context (Sternberg, 1999; Ferrando et al., 2016). Successful intelligence involves analytical, creative, and practical intelligence, each comprising different types of intelligence. Analytical intelligence refers to the ability to solve problems, reason correctly, and judge the quality of ideas, often for problems that require a single solution (Hunt, 2008; Sternberg, 2018). However, creative intelligence refers to coming up with new ideas in novel or unusual situations (Sternberg, 1999). Unlike analytical and creative intelligence, practical intelligence refers to solving everyday problems, or in other words, being street smart (Sternberg and Grigorenko, 2002). Although this construct view of intelligence has been widely accepted and recommended to be considered by educators (Hunt, 2008), there are also criticism and doubt about the scientific basis that it has been grounded on, especially the validity of practical intelligence as a good predictor of future success (Gottfredson, 2003). While acknowledging this controversy, we believe that the breaking down of the intelligence into identifiable components as has been illustrated by Grigorenko and Sternberg (2001) can help identify more students to be served in gifted programs, therefore it is more appropriate for gifted education in Arab countries.

While emotional, social, and successful intelligence refer to certain processes and skills, the implicit theory of intelligence refers to one's beliefs about intelligence, and whether they are fixed or malleable (Dweck and Leggett, 1988). Thus, the implicit theory of intelligence-or just implicit intelligencecan be considered a belief system of one's own intelligence ( $\mathrm{Da}$ Fonseca et al., 2004; Blackwell et al., 2007). The general idea here is that people have their own implicit theories against which they evaluate themselves and others (Sternberg, 1985). In a meta-analysis study performed by Burnette et al. (2013) found that although individuals construct their implicit theories as a result of self-evaluation and their accomplishments, the association between implicit theories with self-regulation are not straightforward. Sisk et al. (2018) reported two meta-analysis studies where they found the correlation between growth mindset and academic achievement was very weak, which is almost identical to what Burnette et al. (2013) found. However, other researchers found that mind-set can highly affect achievement (Yeager and Walton, 2011). Although the theory of mindset has many variations about its impact, it may be useful to examine other relevant variables, especially the type of intelligence, and its impact along with a growth mindset in achievement.

\section{Impact of Gender and Grade Level on Intelligence}

For several decades, there have been a multitude of studies on gender differences in different types of intelligence (Yildiz et al., 2020). One recent study found that intelligence in males and females has different neural underpinnings (Jiang et al., 2020).
Lynn (2017) also argued that there are no significant differences in the intelligence of males and females up to the age of 15 , after which males show increased intelligence. Furthermore a meta-analysis study found that gender does not mediate the relationship between intelligence and grades, i.e., a measure of academic performance (Roth et al., 2015).

With regard to emotional intelligence, female participants have outperformed male participants in several studies (Schutte et al., 1998; Petrides and Furnham, 2000; Gerber, 2004; BarOn, 2006; Tapia and Marsh, 2006; Sünbül, 2007). The same findings hold true for gifted students, as gifted female students score higher than gifted male students on emotional intelligence (Abdulla Alabbasi et al., 2020). A recent study in Iran found that female students scored higher on many aspects of emotional intelligence than male students (Meshkat and Nejati, 2017). Moreover, Herrera et al. (2019) found that Spanish female and male students differed in emotional intelligence (Fischer et al., 2018). In addition to students, Shehzad and Mahmood (2013) found that female teachers in Pakistan scored higher than male teachers in interpersonal skills, a subdomain of emotional intelligence. However, no differences were found between the female and male teachers in the other subscales: intrapersonal skills, stress management, adaptability, and general mood. It was also found that emotional differences between males and females are mediated by age (Fernández-Berrocal et al., 2012).

However, not all studies have reported that female participants outperformed male participants in emotional intelligence (AlHamdan et al., 2017). For example, a recent study found that males outperform females on some measures of the Wechsler Adult Intelligence Scale's measures of intelligence (Pezzuti et al., 2020). Furthermore, Saygili (2015) found no differences between male and female gifted students in emotional intelligence.

Results on social intelligence are similar to those of emotional intelligence, as most studies have shown that females outperform males in this type of intelligence. For example, Groves (2005) found that female leaders scored higher than male leaders on measures of social intelligence, while other studies have found that female students possess higher social intelligence than male students (Saxena and Jain, 2013; Fellmann and Redolfi, 2017; Fida et al., 2018). However, unlike the previously discussed studies, Malik et al. (2018) found that male students outperformed female students in Pakistan on measures of social intelligence.

There have been fewer studies on successful intelligence in comparison to emotional and social intelligence. As mentioned above, successful intelligence involves analytical, creative, and practical intelligence. Some studies found no differences in successful intelligence between male and female gifted students (Hein et al., 2015; Mourgues et al., 2015). As for the implicit theory of intelligence, a recent investigation found no differences between male and female gifted students in implicit intelligence (Makel et al., 2015).

Unlike gender differences, there are fewer studies on the impact of grade-level differences on intelligence. Some prior studies have found a relationship between age and social intelligence (Peixoto, 2013), likely suggesting that students with a higher grade level may score higher on measures of social intelligence than students at a lower grade level. More specifically, 
Peixoto (2013) found that older students were better at social problem solving than younger students. Sünbül (2007) did not find any significant differences between first- and fourth-level students in emotional intelligence.

\section{Academic Performance and Intelligence}

Several studies have shown that academic performance is related to different kinds of intelligence. One meta-analysis study found that the relationship between academic performance and intelligence depends on the kind of intelligence (Roth et al., 2015). For example, emotional intelligence has been found to predict academic performance (Sünbül, 2007; Naghavi and Redzuan, 2011; Jiménez-Morales and López-Zafra, 2013; De Haro Garcia and Costa, 2014; MacCann et al., 2020).

Furthermore, some studies have reported a positive relationship between academic performance and social intelligence in leaders of sales organizations (Boyatzis et al., 2012). Similarly, several studies have shown that successful intelligence-i.e., analytical, creative, and practical skills-is also related to academic performance (Tan et al., 2012; Aljughaiman and Ayoub, 2013, Ayoub, 2018; Mandelman et al., 2013, 2015; Sternberg et al., 2014; Mourgues et al., 2015). Thus, academic performance is also related to implicit theories of intelligence (Blackwell et al., 2007; Todor, 2014), such that beliefs in one's skills can motivate them to study harder and achieve higher grades. In other words, it is likely that the belief that one's intelligence is malleable can motivate students to work harder to achieve a better academic performance.

\section{Gifted Students and Intelligence}

Many studies have been conducted on measures of intelligence in gifted students over the past several decades (Zeidner and Matthews, 2017; Matthews et al., 2018). Generally speaking, gifted students show high intelligence scores (Fernandez et al., 2017). Some studies have argued that gifted students score higher on multiple measures of intelligence than non-gifted students (Basak and Bengi, 2013).

Most studies, including a recent meta-analysis, have demonstrated that gifted students score higher than non-gifted students on emotional intelligence measures (Abdulla Alabbasi et al., 2020). However, this is not always the case. For instance, a recent investigation reported that gifted students score lower on measures of emotional intelligence than non-gifted students (Casino-Garcia et al., 2019). Similar to emotional intelligence, studies have been conducted on social intelligence in gifted students (Jones and Day, 1996). These studies have demonstrated that gifted students also score higher than non-gifted students on measures of social intelligence (de França-Freitas et al., 2014). Importantly, it is not clear in the literature how high emotional or social intelligence scores help students achieve high academic performances.

It has also been argued that gifted students have strong successful intelligence skills (Ferrando et al., 2016; Sternberg, 2019). Ayoub and Aljughaiman (2016) found that successful intelligence plays a role in academic performance in gifted students, although less than that of emotional intelligence.
Furthermore, it has been found that giftedness in students is related to implicit beliefs about intelligence (Snyder et al., 2013).

\section{Current Study}

Given that there is a dearth of studies, especially in Arab countries, investigating the impact of grade level on intelligence, as well as the impact of different kinds of intelligence on academic performance, the current study will study the impact of gender and grade level on emotional, social, successful, and implicit intelligence.

\section{MATERIALS AND METHODS}

\section{Participants}

The education system in Saudi Arabia is compulsory for individuals from 6 years of age, and requires gender segregation during teaching in public education schools, which means that there are separate schools for boys and separate schools for girls. Students generally study math, science, literature, history, Arabic language, and Islamic studies from grade one to twelve. The sample included 174 fifth (41.4\%) and sixth (58.6\%) graders-53.4\% male and $46.6 \%$ female-participating in summer enrichment programs held annually by Mawhiba, a giftedness organization in Saudi Arabia. Summer enrichment programs are also separated based on gender, however, the curriculum content in these programs is based on STEM only. The participants were selected for the study according to two criteria: (a) being among the top 5\% on the ability test designed for the Saudi Arabian learning environment and (b) a general studies achievement test score between 90 and 100\%. The scales of emotional, social, analytical, creative, and practical intelligence, as well as implicit theories of intelligence, were administered. The inventory was distributed to three teachers, with each of them asked to assess students' performances during their participation in these programs.

\section{Measures}

In this study, the following scales were used: the emotional intelligence scale, the social intelligence scale, the Aurora Battery, the implicit theories of intelligence scale, and the performance assessment scale. Each one is described in detail below.

\section{The Emotional Intelligence Scale}

The emotional intelligence scale was developed by Ayoub and Aljughaiman (2016). It is a 22-item self-report measure rated on a five-point Likert scale ranging from strongly agree (5) to strongly disagree (1). The top score was 110 . The reliability coefficient (Cronbach's $\alpha$ ) of the scale reached 0.86 .

\section{The Social Intelligence Scale}

The social intelligence scale (Silvera et al., 2001) is a 21 -item self-report scale that was designed to measure a broad array of cognitive avoidance strategies frequently used when faced with intrusive thoughts. Participants rated the applicability of each item on a five-point Likert scale, ranging from strongly agree 
(5) to strongly disagree (1). The top score was 105, with the higher scores indicating greater social intelligence. Cronbach's $\alpha$ was 0.89 .

\section{The Aurora Battery}

The Aurora Battery is an assessment designed for children aged 9-12 years. It is based on the theory of successful intelligence, and one of its uses is for the identification of gifted students (Chart et al., 2008). The battery is composed of two parts: the first (Aurora-g Battery) measures general intelligence through series, analogy, and classification tests; the second (Aurora-a Battery) measures analytical, creative, and practical skills. Both are paperand-pencil assessments designed for students in elementary and middle school (Aljughaiman and Ayoub, 2012), translated into Arabic and standardized for Saudi Arabia. In the current study, the researchers focused on Aurora-a. There were two subtests for the assessment of analytical ability-floating boats: identify matching patterns among connected boats, consisting of five multiple-choice items; and metaphors: explain how two somewhat unrelated things are alike, consisting of 10 open-ended items - two for the assessment of creative ability-book covers: interpret an abstract picture and invent a story to accompany it, consisting of five open-ended items; and number talk: imagine reasons for various described social interactions between numbers, consisting of seven open-ended items - and two for the assessment of practical ability-paper cutting: identify the proper unfolded version of a cut piece of paper, consisting of 10 multiplechoice items; and maps: trace the best carpooling routes to take between friends' houses and destinations, consisting of 10 rightor-wrong items. The reliability coefficient of the Aurora-a Battery using Cronbach's $\alpha$ was 0.88 for analytical intelligence, 0.82 for creative intelligence, and 0.85 for practical intelligence.

\section{The Implicit Theories of Intelligence Scale}

The implicit theories of intelligence scale was developed by Dweck (2000). It consists of five items assessing incremental theories, e.g., performing a task successfully can help develop your intelligence, and five assessing entity theories, e.g., you are born with a fixed amount of intelligence. The overall scores of the scale were also used in this study. Participants were asked to report their agreement on a five-point Likert scale from strongly agree (5) to strongly disagree (1). The top score was 50. Cronbach's $\alpha$ was 0.82 .

\section{The Performance Assessment Inventory}

The performance assessment inventory is a self-report inventory used to assess students' performances. It was developed by Ayoub and Aljughaiman (2016) and includes a rubric of ten indicators: scientific thinking, research skills, problem solving, discussions, presentations, projects, motivation, leadership, autonomy, and teamwork. This rubric was used by the three raters to evaluate the portfolios created by the students during the summer enrichment programs. The raters were asked to assess the students' portfolios on the scale's indicators, from 0 (incorrect response) to 10 (full mark). The top score was 100 . These performance assessment inventories were checked by a number of professionals in the field of giftedness. Based on a sample of 30 students, the percentages of agreement between the raters were as follows: rater 1-rater 2: 98\%; rater 1-rater 3: 94\%; and rater 2-rater 3: 96\%. Cronbach's $\alpha$ was 0.69 .

\section{RESULTS}

\section{Correlational Analyses}

Table 1 presents the mean and standard deviations of all variables, as well as the correlations among them. Performance was positively associated with emotional intelligence $(r=0.78$, $p<0.01)$, social intelligence $(r=0.54, p<0.01)$, analytical intelligence $(r=0.74, p<0.01)$, creative intelligence $(r=0.71$, $p<0.01)$, practical intelligence $(r=0.67, p<0.01)$, and the implicit theories of intelligence $(r=0.73, p<0.01)$. In addition, these variables were all significantly positively correlated with one another ( $r$ ranged from 0.41 to $0.83, p<0.01$ ). Thus, performance, social, emotional, practical, creative, and analytical intelligence, and implicit theories of intelligence formed a network of interrelated variables.

\section{Gender and Grade Effects}

Prior to conducting the analyses, assumption testing for MANOVA was conducted, with no serious violations noted. Then, the first MANOVA (Table 2), treating gender and grade level as independent variables, and emotional intelligence, social intelligence, analytical intelligence, creative intelligence, practical intelligence, and implicit intelligence as dependent variables, was conducted.

The results revealed significant main effects for grade, $F(7,164)=2.931, p<0.01 ;$ Wilks' Lambda $=0.89, \eta^{2}=0.11$. The Wilks' Lambda criterion indicated that the variables were non-significantly affected by gender, $[F(7,164)=0.691, p>0.05$; Wilks' Lambda $=0.03]$ or overall gender-grade interaction, $[F(7,164)=0.39, p>0.05$; Wilks' Lambda $=0.02]$. Univariate $F$-tests indicated significant differences between the fifth-grade and sixth-grade students in social intelligence, $F(1,174)=5.90$, $p<0.05$, analytical intelligence, $F(1,174)=10.06, p<0.01$, creative intelligence, $F(1,174)=11.24, p<0.01$, practical intelligence, $F(1,174)=7.25, p<0.01$, implicit intelligence, $F(1,174)=11.26, p<0.01$, and performance, $F(1,174)=6.28$, $p<0.05$. The sixth-grade students reported higher levels than the fifth-grade students on all of these variables. The effect sizes for significant $F$ s, $\eta^{2}$ ranged from 0.034 to 0.062 , while the results indicated that there were non-significant differences between the fifth-grade students and the sixth-grade students in emotional intelligence, $F(1,174)=1.40, p>0.05$.

\section{DISCUSSION}

The current study aimed to analyze the correlations between students' academic performance, different kinds of intelligence-emotional, social, analytical, creative, and practical-and their implicit beliefs about intelligence; determine 
TABLE 1 | Correlations, means, and standard deviations for all variables.

\begin{tabular}{|c|c|c|c|c|c|c|c|c|c|}
\hline Variable & 1 & 2 & 3 & 4 & 5 & 6 & 7 & $M$ & $S D$ \\
\hline (1) Performance & - & & & & & & & 75.33 & 11.95 \\
\hline (2) Emotional intelligence & $0.78^{\star \star}$ & - & & & & & & 51.77 & 16.74 \\
\hline (3) Social intelligence & $0.54^{\star *}$ & $0.41^{\star *}$ & - & & & & & 69.06 & 12.60 \\
\hline (4) Analytical intelligence & $0.74^{\star \star}$ & $0.57^{\star *}$ & $0.58^{\star \star}$ & - & & & & 30.75 & 6.05 \\
\hline (5) Creative intelligence & $0.71^{\star \star}$ & $0.72^{\star \star}$ & $0.55^{\star \star}$ & $0.62^{\star \star}$ & - & & & 36.28 & 6.75 \\
\hline (6) Practical intelligence & $0.67^{\star \star}$ & $0.76^{\star \star}$ & $0.46^{\star \star}$ & $0.67^{\star \star}$ & $0.78^{\star \star}$ & - & & 20.33 & 7.13 \\
\hline (7) Implicit intelligence & $0.73^{\star \star}$ & $0.69^{\star \star}$ & $0.45^{\star \star}$ & $0.72^{\star \star}$ & $0.70^{\star \star}$ & $0.83^{\star \star}$ & - & 27.33 & 8.55 \\
\hline
\end{tabular}

${ }^{*} p<0.05,{ }^{* *} p<0.01$.

students' profiles; and investigate gender and grade-level differences in performance.

First, the results revealed statistically significant correlations $(p<0.01)$ between performance as a dependent variable and emotional intelligence, social intelligence, analytical intelligence, creative intelligence, practical intelligence, and implicit beliefs about intelligence as independent variables. These results are in agreement with the findings of other studies (Blackwell et al., 2007; Boyatzis and Saatcioglu, 2007; Burnette et al., 2013; Mohammadyari and Sherzvani, 2013; Kaur and Jiwan, 2014; Sternberg et al., 2014; Mandelman et al., 2015). Moreover, the results showed a statistically significant correlative relationship $(p<0.01)$ among emotional, social, analytical, creative, practical, and implicit intelligence.

In general, the data shows a highly significant correlation among all variables in this article. As expected, these results support the findings revealed in the previous literature, which indicate that there is a positive, direct association between students' implicit theory, their academic performance, and different types of intelligence (Rammstedt and Rammsayer, 2000; Blackwell et al., 2007; Chen and Wong, 2015; Alesi et al., 2016; Abushalbaq et al., 2021). Therefore, it is not just general intelligence and performance that is positively associated with incremental views of intelligence, but also other types mentioned this study. These results should be viewed within the context of this study, which focuses primarily on gifted students. This might mean that in general, students with strong abilities and who perform well in school tend to have incremental views of intelligence. Also, it is not just with general intelligence but also with their emotional, social, practical, analytical, and creative intelligence that might justify the increased association among these factors.

Understanding these associations is crucial for educators who are working in the gifted education field and for parents. Identification tools and assessments should consider collecting more information about the status of students' beliefs about intelligence and academic performance. This information might play an important role in improving the quality of services and interventions that are provided to students. Some students participating in gifted programs are not able keep pace with the challenges provided and often leave the program after a short period of time (Moore et al., 2005). One possible reason for this is their negative view of their own intelligence and believing that their abilities are fixed.
The results of this study also support using alternative assessments such as practical, creative, and analytical tools, which may help identify students with special needs. Many gifted students may not be identified as such due to their poor performance in school and in general intelligence tests, especially those students with disabilities and disadvantaged background (Aljughaiman, 2021).

The current study investigated the impact of gender and grade level on emotional, social, analytical, creative, practical, and implicit intelligence. Regarding gender differences, the findings indicated that there were no significant differences between the male and female students in emotional, social, successful, or implicit intelligence. This was not in agreement with the findings of some previous studies (Schutte et al., 1998; Petrides and Furnham, 2000; Gerber, 2004; Bar-On, 2006; Tapia and Marsh, 2006; Sünbül, 2007; Meshkat and Nejati, 2017; Abdulla Alabbasi et al., 2020), which could be due to differences in participants, as the current study recruited gifted students only. However, the results of the current study did agree with the results of some other studies, which indicated that there were no genderaffected differences in emotional intelligence (Saygili, 2015), social intelligence (Meece et al., 2009), successful intelligence (Hein et al., 2015; Mourgues et al., 2015), or implicit intelligence (Makel et al., 2015). However, it is worth mentioning that the results regarding emotional intelligence are not in agreement with other studies in the field, which indicated that women have higher emotional intelligence than men (Cabello et al., 2016). The small number of participants in this study may be one possible explanation for this finding. Also, in this study, we did not find the association of intelligence and ability with girls more than boys as was found in several other studies (e.g., Pepi et al., 2006). In summary, different types of intelligence and their implicit theories do not vary based on gender.

David (2017) mentioned that from 1999 to 2007, the Saudi Ministry of Education offered special programs for 66,000 students (Al Qarni, 2010). Al Qarni (2010) determined that the enormous amount of investment in gifted education in Saudi Arabia did not justify the comparatively poor results. Additionally, the Saudi National Research Center for Giftedness and Creativity provided critiques of the current state of gifted education in Saudi Arabia. Muammar (2015) concluded that intellectually gifted students lacked essential skills to prevail in the global competitive economy. Alamer 
(2014) focused on the three most important difficulties that the Saudi Arabian education system must overcome to properly nurture its gifted students: (a) the nature of the Saudi educational system, (b) the structure of the curricula, and (c) the lack of appropriate teachers. There is also a shortage of suitable learning materials. Alamer (2014) concluded that education in Saudi Arabia is still behind global standards, and the balance between Islamic and Arabic studies and scientific subjects is still uneven. In addition, the preparation and training programs of Saudi teachers to deal with students - especially gifted students - still need improvement.

\section{CONCLUSION}

With regard to grade level, the findings demonstrated that there were significant differences between the fifth- and sixth-grade students in social, analytical, creative, practical, and implicit. The sixth-grade students reported higher levels than the fifth-grade students on all of these variables. The results of the current study agreed with the results of other studies, which indicated that there were significant associations between age and social intelligence (Peixoto, 2013). Additionally, the findings are in agreement with other studies that have demonstrated that analytical, creative, and practical intelligence scores were positively related to students' grades (Tan et al., 2012; Aljughaiman and Ayoub, 2013; Hein et al., 2015; Mourgues et al., 2015). Some studies have found positive significant associations between age and implicit intelligence (Dweck et al., 1995; Burnette et al., 2013). In general, we did not expect significant differences in these variables due to the small age range. However, one possible explanation for this result is that students in the sixth grade in our study were exposed to gifted programs and services more than students in the fifth grade, because the starting point for gifted education services in Saudi Arabia is the fourth grade. The results of the current study indicated that there were no significant differences between the fifth-grade and sixth-grade students in emotional intelligence. This finding is compatible with the results of Peixoto (2013), who found no significant association between grade level and emotional intelligence. In summary, different types of Intelligences and their implicit theories vary based on grade level.

\section{Limitations and Future Directions}

There are some limitations to this study, such as the small sample size, which is due to the nature of the data collection from the participants in this study. The participants were recruited from an annual teaching event. Thus, the time period was limited and did not allow for the recruitment of a larger sample. Additionally, academic performance was measured using a novel scale developed by the authors of this study. Future research should use a more realistic measure of academic performance, such as grade point average or marks in certain subjects, as in previous studies (Frazier et al., 2019; Kivlighan et al., 2020; Travis et al., 2020; Altwijri et al., 2021; Hegelund et al., 2021). Given that the current
TABLE 2 | MANOVA of dependent variables by gender and grade.

\begin{tabular}{|c|c|c|c|c|c|c|}
\hline Source & Dependent variable & $d f$ & MS & $F$ ratio & $p$ & $\eta^{2}$ \\
\hline \multirow[t]{7}{*}{ Gender } & Emotional intelligence & 1 & 222.461 & 0.791 & 0.375 & 0.005 \\
\hline & Social intelligence & 1 & 102.391 & 0.658 & 0.418 & 0.004 \\
\hline & Analytical intelligence & 1 & 10.019 & 0.289 & 0.591 & 0.002 \\
\hline & Creative intelligence & 1 & 20.948 & 0.484 & 0.487 & 0.003 \\
\hline & Practical intelligence & 1 & 96.119 & 1.969 & 0.162 & 0.011 \\
\hline & Implicit intelligence & 1 & 105.006 & 1.533 & 0.217 & 0.009 \\
\hline & Performance & 1 & 85.148 & 0.61 & 0.436 & 0.004 \\
\hline \multirow[t]{7}{*}{ Grade } & Emotional intelligence & 1 & 393.935 & 1.4 & 0.238 & 0.008 \\
\hline & Social intelligence & 1 & 919.011 & 5.909 & 0.016 & 0.034 \\
\hline & Analytical intelligence & 1 & 348.337 & 10.061 & 0.002 & 0.056 \\
\hline & Creative intelligence & 1 & 486.2 & 11.242 & 0.001 & 0.062 \\
\hline & Practical intelligence & 1 & 353.784 & 7.248 & 0.008 & 0.041 \\
\hline & Implicit intelligence & 1 & 770.831 & 11.257 & 0.001 & 0.062 \\
\hline & Performance & 1 & 877.49 & 6.284 & 0.013 & 0.036 \\
\hline \multirow{7}{*}{$\begin{array}{l}\text { Gender } \\
\text { * Grade }\end{array}$} & Emotional intelligence & 1 & 0.065 & 0 & 0.988 & 0 \\
\hline & Social intelligence & 1 & 12.029 & 0.077 & 0.781 & 0 \\
\hline & Analytical intelligence & 1 & 48.56 & 1.403 & 0.238 & 0.008 \\
\hline & Creative intelligence & 1 & 9.872 & 0.228 & 0.633 & 0.001 \\
\hline & Practical intelligence & 1 & 10.183 & 0.209 & 0.648 & 0.001 \\
\hline & Implicit intelligence & 1 & 49.084 & 0.717 & 0.398 & 0.004 \\
\hline & Performance & 1 & 1.038 & 0.007 & 0.931 & 0 \\
\hline \multirow[t]{7}{*}{ Error } & Emotional intelligence & 170 & 281.289 & & & \\
\hline & Social intelligence & 170 & 155.54 & & & \\
\hline & Analytical intelligence & 170 & 34.622 & & & \\
\hline & Creative intelligence & 170 & 43.249 & & & \\
\hline & Practical intelligence & 170 & 48.812 & & & \\
\hline & Implicit intelligence & 170 & 68.477 & & & \\
\hline & Performance & 170 & 139.64 & & & \\
\hline \multirow[t]{7}{*}{ Total } & Emotional intelligence & 173 & & & & \\
\hline & Social intelligence & 173 & & & & \\
\hline & Analytical intelligence & 173 & & & & \\
\hline & Creative intelligence & 173 & & & & \\
\hline & Practical intelligence & 173 & & & & \\
\hline & Implicit intelligence & 173 & & & & \\
\hline & Performance & 173 & & & & \\
\hline
\end{tabular}

$N=(173)$. MANOVA, multivariate analysis of variance.

study recruited primary school students, future research should also investigate intelligence in gifted high school students. Furthermore, future research should investigate grade-level differences, as there are a limited number of studies on this topic. Moreover, it is important to investigate how different types of intelligence develop in students over the years, and how it relates to their academic performance. In addition, future research should explain exactly how each type of intelligence contributes to academic performance for primary school, high school, and university students. For example, emotional and social intelligence may help students work in teams to effectively carry out projects.

Additionally, one of the main limitations of the current study was that the emotional intelligence (EI) scale, the social intelligence (SI) scale, and the performance assessment (PA) 
inventory were all self-reported, and there is a problem in their reliability. This is in line with Fischer et al. (2018), who summarized their finding as Men, however, more strongly perceived non-target emotions to be present than women. Also, the lower scores of men in selfreported EI were not related to their actual perception of target emotions but rather to the perception of non-target emotions.

\section{DATA AVAILABILITY STATEMENT}

The raw data supporting the conclusions of this article will be made available by the authors, without undue reservation, to any qualified researcher.

\section{REFERENCES}

Abdulla Alabbasi, A. M. A., Ayoub, A. E. A., and Ziegler, A. (2020). Are gifted students more emotionally intelligent than their non-gifted peers? A metaanalysis. High Abil. Stud. 32, 189-217. doi: 10.1080/13598139.2020.1770704

Abushalbaq, O. M., Khdour, H. Y., Abo Hamza, E. G., Moustafa, A. A., and Herzallah, M. M. (2021). Investigating Principal Working Memory Features in Generalized, Panic, and Social Anxiety Spectrum Disorders. Front. Psychiatry 12:701412. doi: 10.3389/fpsyt.2021.701412

Al Qarni, M. A. (2010). Evaluation of Provisions for Gifted Students in Saudi Arabia. Wollongong: University of Wollongong.

Alamer, S. M. (2014). Challenges facing gifted students in Saudi Arabia. Res. Hum. Soc. Sci. 4, 107-112.

Alesi, M., Rappo, G., and Pepi, A. (2016). Investigating the improvement of decoding abilities and working memory in children with incremental or entity personal conceptions of intelligence: two case reports. Front. Psychol. 6:1939. doi: 10.3389/fpsyg.2015.01939

Al-Hamdan, N. S., Ahmed Al-Jasim, F., and Abdulla, A. M. (2017). Assessing the emotional intelligence of gifted and talented adolescent students in the Kingdom of Bahrain. Roeper Rev. 39, 132-142. doi: 10.1080/02783193.2017. 1289462

Aljughaiman, A. (2021). Twice Exceptional Students: Identification and Education. Alobaican. Riyadh: Al Obeikan.

Aljughaiman, A. M., and Ayoub, A. E. A. (2012). The effect of an enrichment program on developing analytical, creative, and practical abilities of elementary gifted students. J. Educ. Gift. 35, 153-174. doi: 10.1177/016235321244 0616

Aljughaiman, A. M., and Ayoub, A. E. A. (2013). Evaluating the effects of the oasis enrichment model on gifted education: a meta-analysis study. Talent Dev. Excell. 5, 99-113.

Altwijri, S., Alotaibi, A., Alsaeed, M., Alsalim, A., Alatiq, A., Al-Sarheed, S., et al. (2021). Emotional intelligence and its association with academic Success and performance in medical students. Saudi J. Med. Med. Sci. 9, 31-37. doi: 10.4103/ sjmms.sjmms_375_19

Ayoub, A. (2018). The effect of enrichment programs on improving mental flexibility and inventive work behavior for gifted students: a value-added study. Int. J. Interdiscip. Soc. Sci. Stud. 4, 11-24.

Ayoub, A. E. A., and Aljughaiman, A. M. (2016). A predictive structural model for gifted students' performance: a study based on intelligence and its implicit theories. Learn. Individ. Differ. 51, 11-18. doi: 10.1016/j.lindif.2016.08.018

Bar-On, R. (2006). The Bar-On model of emotional-social intelligence (ESI). Psicothema 18, 13-25.

Basak, C., and Bengi, B. (2013). Multiple intelligence theory for gifted education: criticisms and implications. J. Educ. Young Sci. Gift. 1, 1-12. doi: 10.17478/jeysg. 201329002

Blackwell, L. S., Trzesniewski, K. H., and Dweck, C. S. (2007). Implicit theories of intelligence predict achievement across an adolescent transition: a longitudinal

\section{ETHICS STATEMENT}

The studies involving human participants were reviewed and approved by Arabian Gulf University. The patients/participants provided their written informed consent to participate in this study.

\section{AUTHOR CONTRIBUTIONS}

AAy ran statistical analyses and wrote the Method and Results' sections. AAlj wrote the Literature Review and Discussion sections. AAla addressed the reviewers comments and revised the Introduction and the Literature Review. Finally, EA contributed to writing the Introduction and the Discussion. All authors contributed to the article and approved the submitted version.

study and an intervention. Child Dev. 78, 246-263. doi: 10.1111/j.1467-8624. 2007.00995.x

Boyatzis, R. E., and Saatcioglu, A. (2007). A 20-year view of trying to develop emotional, social and cognitive intelligence competencies in graduate management education. J. Manag. Dev. 27, 92-108.

Boyatzis, R. E., Good, D., and Massa, R. (2012). Emotional, social, and cognitive intelligence and personality as predictors of sales leadership performance. J. Leadersh. Organ. Stud. 19, 191-201. doi: 10.1177/1548051811435793

Burnette, J. L., O’Boyle, E. H., Van Epps, E. M., Pollack, J. M., and Finkel, E. J. (2013). Mind-sets matter: a meta-analytic review of implicit theories and self-regulation. Psychol. Bull. 139, 655-701. doi: 10.1037/a002 9531

Buşu, A. (2020). Emotional intelligence as a type of cognitive ability. Revista de ştiinţe Politice. Rev. Sci. Polit. 66, 204-215.

Cabello, R., and Fernández-Berrocal, P. (2015). Implicit theories and ability emotional intelligence. Front. Psychol. 6:700. doi: 10.3389/fpsyg.2015.00700

Cabello, R., Sorrel, M., Fernández-Pinto, I., Extremera, N., and FernándezBerrocal, P. (2016). Age and gender differences in ability emotional intelligence in adults: a cross-sectional study. Dev. Psychol. 52, 1486-1492. doi: 10.1037/ dev0000191

Cantero, M. J., Banuls, R., and Viguer, P. (2020). Effectiveness of an emotional intelligence intervention and its impact on academic performance in Spanish pre-adolescent elementary students: results from the EDI program. Int. J. Environ. Res. Public Health 17:7621. doi: 10.3390/ijerph17207621

Carroll, J. B. (2003). "The higher-stratum structure of cognitive abilities: Current evidence supports g and about ten broad factors," in The scientific study of general intelligence: Tribute to Arthur R. Jensen, ed. H. Nyborg (Oxford: Pergamon Press), 5-22. doi: 10.1016/b978-008043793-4/ 50036-2

Casino-Garcia, A. M., Garcia-Perez, J., and Llinares-Insa, L. I. (2019). Subjective emotional well-being, emotional intelligence, and mood of gifted vs. unidentified students: a relationship model. Int. J. Environ. Res. Public Health 16:3266 doi: 10.3390/ijerph16183266

Cattell, R. B. (1963). Theory of fluid and crystallized intelligence: a critical experiment. J. Educ. Psychol. 54, 1-22. doi: 10.1037/h0046743

Chart, H., Grigorenko, E. L., and Sternberg, R. J. (2008). "Identification: The Aurora Battery," in Critical Issues and Practices in Gifted Education, ed. C. M. C. J. A. Plucker (Woodway: Prufrock), 281-301.

Chen, J. A., and Tutwiler, M. S. (2017). Implicit theories of ability and self-efficacy: testing alternative social cognitive models to science motivation. Zeitschrift für Psychologie 225, 127-136. doi: 10.1027/2151-2604/a000289

Chen, W. W., and Wong, Y. L. (2015). Chinese mindset: theories of intelligence, goal orientation and academic achievement in Hong Kong students. Educ. Psychol. 35, 714-725. doi: 10.1080/01443410.2014.893559

Claro, S., Paunesku, D., and Dweck, C. S. (2016). Growth mindset tempers the effects of poverty on academic achievement. Proc. Natl. Acad. Sci. U. S. A. 113, 8664-8668. doi: 10.1073/pnas.1608207113 
Costa, A., and Faria, L. (2018). Implicit theories of intelligence and academic achievement: a meta-analytic review. Front. Psychol. 9:829. doi: 10.3389/fpsyg. 2018.00829

Credé, M., Tynan, M. C., and Harms, P. D. (2017). Much ado about grit: a metaanalytic synthesis of the grit literature. J. Pers. Soc. Psychol. 113, 492-511. doi: $10.1037 / \mathrm{pspp} 0000102$

Da Fonseca, D., Cury, F., Bailly, D., and Rufo, M. (2004). Rôle des théories implicites de l'intelligence chez les élèves en situation d'apprentissage [Role of the implicit theories of intelligence in learning situations]. L'Encéphale 30, 456-463. doi: 10.1016/s0013-7006(04)95460-7

David, H. (2017). "Gifted education in the Middle East," in APA Handbook of Giftedness and Talent, eds S. Pfeiffer, E. Shaunessy-Dedrick, and M. Foley Nicpon (Washington: APA Books), 113-129. doi: 10.1037/0000038-008

de França-Freitas, M. L. P., Del Prette, A., and Del Prette, Z. A. P. (2014). Social skills of gifted and talented children. Estud. Psicol. 19, 288-295. doi: 10.1590/ S1413-294X2014000400006

De Haro Garcia, J. M., and Costa, J. C. (2014). Does trait emotional intelligence predict unique variance in early career success beyond IQ and personality?. J. Career Assess. 22, 715-725.

Deary, I. J., Strand, S., Smith, P., and Fernandes, C. (2007). Intelligence and educational achievement. Intelligence 35, 13-21. doi: 10.1016/j.intell.2006.02. 001

Deary, I. J. (2000). Looking Down On Human Intelligence: From Psychometrics to the Human Brain. Oxford: Oxford University Press.

Diseth, A, Meland, E., and Breidablik, H. J. (2014). Self-beliefs among students: grade level and gender differences in self-esteem, self-efficacy and implicit theories of intelligence. Learn. Individ.Differ. 35, 1-8. doi: 10.1016/j.lindif.2014. 06.003

Durlak, J. A., Weissberg, R. P., Dymnicki, A. B., Taylor, R. D., and Schellinger, K. B. (2011). The impact of enhancing students' social and emotional learning: a meta-analysis of school-based universal interventions. Child Dev. 82, 405-432. doi: 10.1111/j.1467-8624.2010.01564.x

Dutton, E., te Nijenhuis, J., and Roivainen, E. (2014). Solving the puzzle of why Finns have the highest IQ, but one of the lowest number of Nobel prizes in Europe. Intelligence 46, 192-202. doi: 10.1016/j.intell.2014.06.006

Dweck, C. S. (2000). Self-theories: Their Role in Motivation, Personality and Development. Oxfordshire: Taylor \& Francis.

Dweck, C. S. (2012). "Implicit theories," in The Handbook of Theories of Social Psychology, eds P. Van Lange, A. Kruglanski, and T. Higgins (California: SAGE Publications Ltd), 43-62.

Dweck, C. S., Chiu, C., and Hong, Y. (1995). Implicit theories and their role in judgments and reactions: a word from two perspectives. Psychol. Inj. 6, 267-285.

Dweck, C. S., and Leggett, E. L. (1988). A social-cognitive approach to motivation and personality. Psychol. Rev. 95, 256-273. doi: 10.1037/0033-295x.95.2.256

Erden, G., Yigit, I., Celik, C., and Guzey, M. (2020). The diagnostic utility of the Wechsler Intelligence Scale for Children-Fourth Edition (WISC-IV) in identification of gifted children. J. Gen. Psychol. 1-20. [Online ahead of print] doi: 10.1080/00221309.2020.1862038

Erdley, C. A., and Dweck, C. S. (1993). Children's implicit personality theories as predictors of their social judgments. Child Dev. 64, 863-878.

Fellmann, F., and Redolfi, E. (2017). Aspects of sex differences: social intelligence vs. creative intelligence. Adv. Anthropol. 7, 298-317. doi: 10.4236/aa.2017.7 4017

Fernandez, E., Garcia, T., Arias-Gundin, O., Vazquez, A., and Rodriguez, C. (2017). Identifying gifted children: congruence among different IQ measures. Front. Psychol. 8:1239. doi: 10.3389/fpsyg.2017.01239

Fernández-Berrocal, P., Cabello, R., Castillo, R., and Extremera, N. (2012). Gender differences in emotional intelligence: the mediating effect of age. Behav. Psychol. 20, 77-89.

Ferrando, M., Ferrándiz, C., Llor, L., and Sainz, M. (2016). Successful intelligence and giftedness: an empirical study. An. Psicol. 32, 672-682.

Fida, A., Ghaffar, A., Zaman, A., and Satti, A. N. (2018). Gender comparison of emotional intelligence of university students. J. Educ. Educ. Dev. 5, 172-188. doi: 10.22555/joeed.v5i1.2046

Fischer, A. H., Kret, M. E., and Broekens, J. (2018). Gender differences in emotion perception and self-reported emotional intelligence: a test of the emotion sensitivity hypothesis. PLoS One 13:e0190712. doi: 10.1371/journal. pone.0190712
Flanagan, D. P., and Harrison, P. L. (eds) (2012). Contemporary Intellectual Assessment: Theories, Tests, and Issues. New York: Guilford Press.

Frazier, P., Gabriel, A., Merians, A., and Lust, K. (2019). Understanding stress as an impediment to academic performance. J. Am. Coll. Health 67, 562-570. doi: 10.1080/07448481.2018.1499649

Garlick, D. (2002). Understanding the nature of the general factor of intelligence: the role of individual differences in neural plasticity as an explanatory mechanism. Psychol. Rev. 109, 116-136. doi: 10.1037/0033-295X.109. 1.116

Gerber, C. (2004). The relationship between emotional intelligence and success in school for a sample of eighth grade students. Ph.D. thesis. New Jersey: Fairleigh Dickinson University.

Goleman, D. (2006). Social Intelligence: The New Science of Human Relationships. London: Arrow Books.

Gomes, C. M. A., Golino, H. F., and Menezes, I. G. (2014). Predicting school achievement rather than intelligence: does metacognition matter?. Psychology 5, 1095-1110. doi: 10.1186/s12913-016-1423-5

Gonzalez-Trevino, I. M., Nunez-Rocha, G. M., Valencia-Hernandez, J. M., and Arrona-Palacios, A. (2020). Assessment of multiple intelligences in elementary school students in Mexico: an exploratory study. Heliyon 6:e03777. doi: 10. 1016/j.heliyon.2020.e03777

Gottfredson, L. S. (2003). Dissecting practical intelligence theory: its claims and evidence. Intelligence 31, 343-397. doi: 10.1016/s0160-2896(02)00085-5

Gottfredson, L. S. (2005). "Implications of cognitive differences for schooling within diverse societies," in Comprehensive Handbook of Multicultural School Psychology, eds C. L. Frisby and C. R. Reynolds (Hoboken: Wiley), 517-554.

Gottfredson, L. S. (2018). "g theory: How recurring variation in human intelligence and the complexity of everyday tasks create social structure and the democratic dilemma," in The Nature of Human Intelligence, ed. R. J. Sternberg (Cambridge: Cambridge University Press), 130-151.

Grieve, R., and Mahar, D. (2013). Can social intelligence be measured? Psychometric properties of the Tromsø social intelligence scale - English version. Ir. J. Psychol. 34, 1-12. doi: 10.1080/03033910.2012.737758

Grigorenko, E. L., and Sternberg, R. J. (2001). Analytical, creative, and practical intelligence as predictors of self-reported adaptive functioning: a case study in Russia. Intelligence 29, 57-73.

Groves, K. S. (2005). Gender differences in social and emotional skills and charismatic leadership. J. Leadersh. Organ. Stud. 11, 30-36. doi: 10.1177/ 107179190501100303

Gustafsson, J. E., and Undheim, J. O. (1996). "Individual differences in cognitive functions," in Handbook of Educational Psychology, eds D. C. Berliner and R. C. Calfee (New York: Simon \& Schuster Macmillan), 186-242.

Haimovitz, K., and Dweck, C. (2016). Parents' views of failure predict children's fixed and growth intelligence mind-sets. Psychol. Sci. 27, 859-869. doi: 10.1177/ 0956797616639727

Hegelund, E. R., Mortensen, E. L., Flensborg-Madsen, T., Dammeyer, J., Christensen, K., and Johnson, W. (2021). The moderating influence of school achievement on intelligence in young adulthood. Behav. Genet. 51, 45-57. doi: 10.1007/s10519-020-10027-7

Hein, S., Tan, M., Aljughaiman, A., and Grigorenko, E. L. (2015). Gender differences and school influences with respect to three indicators of general intelligence: evidence from Saudi Arabia. J. Educ. Psychol. 107, 486-501.

Herrera, L., Al-Lal, M., and Mohamed, L. (2019). Academic achievement, selfconcept, personality and emotional intelligence in primary education. Analysis by gender and cultural group. Front. Psychol. 10:3075. doi: 10.3389/fpsyg.2019. 03075

Hong, Y., Chiu, C., and Dweck, C. S. (1995). "Implicit theories of intelligence: Reconsidering the role of confidence in achievement motivation," in Efficacy, Agency, and Self-Esteem, ed. M. H. Kernis (New York: Plenum Press), 197-216.

Horn, J. L., and Cattell, R. B. (1966). Refinement and test of the theory of fluid and crystallized general intelligences. J. Educ. Psychol. 57, 253-270. doi: 10.1037/ h0023816

Hunt, E. (2008). Applying the theory of successful intelligence to educationThe good, the bad, and the ogre: commentary on Sternberg et al. (2008). Pers. Psychol. Sci. 3, 509-515. doi: 10.1111/j.1745-6924.2008.00094.x

Jiang, R., Calhoun, V. D., Fan, L., Zuo, N., Jung, R., Qi, S., et al. (2020). Gender differences in Connectome-based predictions of individualized intelligence 
quotient and sub-domain scores. Cereb. Cortex 30, 888-900. doi: 10.1093/ cercor/bhz134

Jiménez-Morales, M., and López-Zafra, E. (2013). Impact of perceived emotional intelligence, social attitudes and teacher expectations on academic performance. Electron. J. Res. Educ. Psychol. 11, 75-98.

Johnson, W., Deary, I. J., Silventoinen, K., Tynelius, P., and Rasmussen, F. (2010). Family background buys an education in Minnesota but not in Sweden. Pers. Psychol. Sci. 21, 1266-1273. doi: 10.1177/0956797610379233

Jones, K., and Day, J. D. (1996). Cognitive similarities between academically and socially gifted students. Roeper Rev. 18, 270-273. doi: 10.1080/ 02783199609553757

Kaur, S., and Jiwan, T. (2014). An exploratory study to assess emotional intelligence and performance of students of selected nursing institute, Ludhiana, Punjab. Asian J. Nurs. Educ. Res. 4, 346-351.

Kivlighan, D. M. III, Schreier, B. A., Gates, C., Hong, J. E., Corkery, J. M., Anderson, C. L., et al. (2020). The role of mental health counseling in college students' academic success: an interrupted time series analysis. J. Couns. Psychol. 68, 562-570. doi: 10.1037/cou0000534

Lam, L., and Kirby, S. (2002). Is emotional intelligence an advantage? An exploration of the impact of emotional and general Intelligence on individual performance. J. Soc. Psychol. 142, 133-143. doi: 10.1080/00224540209603891

Lynn, R. (2017). Sex differences in intelligence: the developmental theory. Mank. Q. 58, 9-42.

Maass, A., D'Ettole, C., and Cadinu, M. (2008). Checkmate? The role of gender stereotypes in the ultimate intellectual sport. Eur. J. Soc. Psychol. 38, 231-245. doi: $10.1002 /$ ejsp.440

MacCann, C., Jiang, Y., Brown, L. E. R., Double, K. S., Bucich, M., and Minbashian, A. (2020). Emotional intelligence predicts academic performance: a metaanalysis. Psychol. Bull. 146, 150-186. doi: 10.1037/bul0000219

Makel, M. C., Snyder, K. E., Thomas, C., Malone, P. S., and Putallaz, M. (2015). Gifted students' implicit beliefs about intelligence and giftedness. Gift. Child Q. 59, 203-212. doi: 10.1177/0016986215599057

Malik, M. A., Siddique, F., and Hussain, S. N. (2018). Exploring the development of social intelligence of students during university years. Pak. J. Educ. 35, 43-58.

Mandelman, S. D., Barbot, B., and Grigorenko, E. L. (2015). Predicting academic performance and trajectories from a measure of successful intelligence. Learn. Individ. Differ. 51, 387-393. doi: 10.3389/fpsyg.2014.00443

Mandelman, S. D., Barbot, B., Tan, M., and Grigorenko, E. L. (2013). Addressing the "quiet crisis": gifted identification with Aurora. Educ. Child Psychol. 30, 101-109.

Martin, A. J., Bostwick, K., Collie, R. J., and Tarbetsky, A. (2017). "Implicit theories of intelligence," in Encyclopedia of Personality and Individual differences, ed. V. Z. H. T. K. Shackelford (Berlin: Springer).

Martínez-Rubio, J. L., Moraleda, E., Rodríguez, B., García-Salmones, L., and Primo, M. (2014). Emotional intelligence vs. general intelligence: aspects to consider in teaching. High. Learn. Res. Commun. 4, 98-111. doi: 10.18870/hlrc.v4i1.199

Matthews, G., Lin, J., Zeidner, M., and Roberts, R. D. (2018). "Emotional intelligence and giftedness," in APA handbook of giftedness and talent, eds E. S. D. S. I. Pfeiffer and M. Foley-Nicpon (Washington: American Psychological Association), 585-600.

Mayer, J. D., Caruso, D. R., and Salovey, P. (1999). Emotional intelligence meets traditional standards for an intelligence. Intelligence 27, 267-298. doi: 10.1016/ s0160-2896(99)00016-1

Mayer, J. D., Salovey, P., Caruso, D. R., and Sitarenios, G. (2001). Emotional intelligence as a standard intelligence. Emotion 1, 232-242. doi: 10.1037/15283542.1.3.232

McClain, M. C., and Pfeiffer, S. I. (2012). Education for the gifted in the United States today: a look at state definitions, policies, and practices. J. Appl. Sch. Psychol. 28, 59-88.

Meece, D., Rivers, L., and Wingate, K. (2009). Establishing Positive Verbal Environments: Strategies for Promoting Social Development Through Positive Guidance. Washington, DC: Education Resources Information Center.

Meshkat, M., and Nejati, R. (2017). Does emotional intelligence depend on gender? A study on undergraduate English majors of three Iranian universities. SAGE Open 7, 1-8. doi: 10.1177/2158244017725796

Mohammadyari, G., and Sherzvani, R. (2013). The relationship between parental styles and emotional intelligence among students. J. Behav. Sci. Asia 5, 19-24.
Moore, J. L. III, Ford, D. Y., and Milner, H. R. (2005). Recruitment is not enough: retaining African American students in gifted education. Gift. Child Q. 49, 51-67. doi: 10.1177/001698620504900106

Mourgues, C. V., Tan, M., Hein, S., Al-Harbi, K., Aljughaiman, A., and Grigorenko, E. L. (2015). The relationship between analytical and creative cognitive skills from middle childhood to adolescence: testing the threshold theory in the Kingdom of Saudi Arabia. Learn. Individ. Differ. 52, 137-147. doi: 10.1016/j. lindif.2015.05.005

Muammar, O. M. (2015). The differences between intellectually gifted and average students on a set of leadership competencies. Gift. Educ. Int. 31, 142-153. doi: $10.1177 / 0261429413498007$

Naghavi, F., and Redzuan, M. (2011). The relationship between gender and emotional intelligence. World Appl. Sci. J. 15, 555-561.

O'Connor, P. J., Hill, A., Kaya, M., and Martin, B. (2019). The measurement of emotional intelligence: a critical review of the literature and recommendations for researchers and practitioners. Front. Psychol. 10:1116. doi: 10.3389/fpsyg. 2019.01116

Peixoto, M. E. (2013). Emotional intelligence and social competence in secondary education students. Ph.D. thesis. Portugal: Universidade do Minho.

Pepi, A., Faria, L., and Alesi, M. (2006). Personal conceptions of intelligence, selfesteem, and school achievement in Italian and Portuguese students. Adolescence 41, 615-631.

Perera, H. N., and DiGiacomo, M. (2013). The relationship of trait emotional intelligence with academic performance: a meta-analytic review. Learn. Individ. Differ. 28, 20-33. doi: 10.1016/j.lindif.2013.08.002

Petrides, K. V., and Furnham, A. (2000). On the dimensional structure of emotional intelligence. Pers. Individ. Differ. 29, 313-320. doi: 10.1016/s0191-8869(99) 00195-6

Pezzuti, L., Tommasi, M., Saggino, A., Dawe, J., and Lauriola, M. (2020). Gender differences and measurement bias in the assessment of adult intelligence: evidence from the Italian WAIS-IV and WAIS-R standardizations. Intelligence 79:101436.

Rammstedt, B., and Rammsayer, T. H. (2000). Sex differences in self-estimates of different aspects of intelligence. Pers. Individ. Differ. 29, 869-880. doi: 10.1016/ S0191-8869(99)00238-X

Renaud-Dubé, A., Guay, F., Talbot, D., Taylor, G., and Koestner, R. (2015). The relations between implicit intelligence beliefs, autonomous academic motivation, and school persistence intentions: a mediation model. Soc. Psychol. Educ. 18, 255-272.

Romero, C., Master, A., Paunesku, D., Dweck, C. S., and Gross, J. J. (2014). Academic and emotional functioning in middle school: the role of implicit theories. Emotion 14, 227-234. doi: 10.1037/a0035490

Roth, B., Becker, N., Romeyke, S., Schäfer, S., Domnick, F., and Spinath, F. M. (2015). Intelligence and school grades: a meta-analysis. Intelligence 53, 118-137. doi: 10.1016/j.intell.2015.09.002

Sanchez-Alvarez, N., Berrios Martos, M. P., and Extremera, N. (2020). A meta-analysis of the relationship between emotional intelligence and academic performance in secondary education: a multistream comparison. Front. Psychol. 11:1517. doi: 10.3389/fpsyg.2020. 01517

Saxena, S., and Jain, R. K. (2013). Social intelligence of undergraduate students in relation to their gender and subject stream. IOSR J. Res. Method Educ. 1, 1-4. doi: $10.9790 / 7388-0110104$

Saygili, G. (2015). The factors affecting emotional intelligence of gifted children. Res. J. Recent Sci. 4, 41-47.

Schmidt, F. L., and Hunter, J. E. (1998). The validity and utility of selection methods in personnel psychology: practical and theoretical implications of 85 years of research findings. Psychol. Bull. 124, 262-274. doi: 10.1037/0033-2909.124. 2.262

Schutte, N. S., Malouff, J. M., Hall, L. E., Haggerty, D. J., Cooper, J. T., Golden, C. J., et al. (1998). Development and validation of a measure of emotional intelligence. Pers. Individ. Differ. 25, 167-177.

Shehzad, S., and Mahmood, N. (2013). Gender differences in emotional intelligence of university teachers. Pak. J. Soc. Clin. Psychol. 11, 16-21.

Silvera, D. H., Martinussen, M., and Dahl, T. I. (2001). The Tromsø social intelligence scale, a self-report measure of social intelligence. Scand. J. Psychol. 42, 313-319. doi: 10.1111/1467-9450.00242 
Sisk, V. F., Burgoyne, A. P., Sun, J., Butler, J. L., and Macnamara, B. N. (2018). To what extent and under which circumstances are growth mind-sets important to academic achievement? Two meta-analyses. Psychol. Sci. 29, 549-571. doi: $10.1177 / 095679761773970$

Snyder, K. E., Barger, M. M., Wormington, S. V., Schwartz-Bloom, R., and Linnenbrink-Garcia, L. (2013). Identification as gifted and implicit beliefs about intelligence: an examination of potential moderators. J. Adv. Acad. 24, 242-258. doi: $10.1177 / 1932202 X 13507971$

Spearman, C. E. (1904). "General intelligence," objectively determined and measured. Am. J. Psychol. 15, 201-293. doi: 10.2307/1412107

Sternberg, R. J. (1985). Implicit theories of intelligence, creativity, and wisdom. J. Pers. Soc. Psychol. 49, 607-627. doi: 10.1037/0022-3514.49.3.607

Sternberg, R. J. (1999). Successful intelligence: finding a balance. Trends Cogn. Sci. 3, 436-442. doi: 10.1016/s1364-6613(99)01391-1

Sternberg, R. J. (2018). Speculations on the role of successful intelligence in solving contemporary world problems. J. Intell. 6:4. doi: 10.3390/jintelligence6010004

Sternberg, R. J. (2019). Teaching and assessing gifted students in STEM disciplines through the augmented theory of successful intelligence. High Abil. Stud. 30, 103-126. doi: 10.1080/13598139.2018.1528847

Sternberg, R. J., and Grigorenko, E. L. (2002). The theory of successful intelligence as a basis for gifted education. Gift. Child Q. 46, 265-277.

Sternberg, R. J., Jarvin, L., Birney, D. P., Naples, A., Stemler, S. E., Newman, T., et al. (2014). Testing the theory of successful intelligence in teaching grade 4 language arts, mathematics, and science. J. Educ. Psychol. 106, 881-899.

Strenze, T. (2007). Intelligence and socioeconomic success: a meta-analytic review of longitudinal research. Intelligence 35, 401-426.

Sünbül, A. M. (2007). "The relationship between emotional intelligence and achievement among 1st and 4th grade faculty students," in Paper presented at the First European SEBCD Conference, (Malta: European SEBCD Conference).

Tan, M., Mourgues, C., Aljughaiman, A., Ayoub, A., Mandelman, S. D., Zbainos, D., et al. (2012). "What the shadow knows: Assessing aspects of practical intelligence with Aurora's Toy Shadows," in Talent Development and Excellence, eds H. Stoeger, A. Aljughaiman, and B. Harder (Münster: LIT).

Tapia, M., and Marsh, G. E. (2006). The effects of sex and grade-point average on emotional intelligence. Psicothema 18, 108-111.

Thorndike, E. L. (1920). Intelligence and its uses. Harper's Mag. 140, 227-235.

Thorndike, R. L., and Stein, S. (1937). An evaluation of the attempts to measure social intelligence. Psychol. Bull. 34, 275-285. doi: 10.1037/h0053850
Todor, I. (2014). Investigating "the old stereotype" about boys/girls and mathematics: gender differences in implicit theory of intelligence and mathematics self-efficacy beliefs. Procedia Soc. Behav. Sci. 159, 319-323. doi: 10.1016/j.sbspro.2014.12.380

Travis, J., Kaszycki, A., Geden, M., and Bunde, J. (2020). Some stress is good stress: the challenge-hindrance framework, academic self-efficacy, and academic outcomes. J. Educ. Psychol. 112, 1632-1643. doi: 10.1037/edu0000478

Worrell, F. C., Subotnik, R. F., Olszewski-Kubilius, P., and Dixson, D. D. (2019). Gifted students. Annu. Rev. Psychol. 70, 551-576. doi: 10.1146/annurev-psych010418-102846

Yeager, D. S., and Walton, G. M. (2011). Social-psychological interventions in education: they're not magic. Rev. Educ. Res. 81, 267-301. 4654311405999 doi: $10.3102 / 003$

Yildiz, M., Öntürk, Y., and Efek, E. (2020). The investigation of multiple intelligence modalities of university students receiving sports education. Asian J. Educ. Train. 6, 246-255.

Zakariasen, K., and Victoroff, K. Z. (2012). Leaders and emotional intelligence: a view from those who follow. Healthc. Manage. Forum 25, 86-90. doi: 10.1016/j. hcmf.2012.05.006

Zeidner, M., and Matthews, G. (2017). Emotional intelligence in gifted students. Gift. Educ. Int. 33, 163-182. doi: 10.1177/0261429417708879

Conflict of Interest: The authors declare that the research was conducted in the absence of any commercial or financial relationships that could be construed as a potential conflict of interest.

Publisher's Note: All claims expressed in this article are solely those of the authors and do not necessarily represent those of their affiliated organizations, or those of the publisher, the editors and the reviewers. Any product that may be evaluated in this article, or claim that may be made by its manufacturer, is not guaranteed or endorsed by the publisher.

Copyright (c) 2022 Ayoub, Aljughaiman, Alabbasi and Abo Hamza. This is an openaccess article distributed under the terms of the Creative Commons Attribution License (CC BY). The use, distribution or reproduction in other forums is permitted, provided the original author(s) and the copyright owner(s) are credited and that the original publication in this journal is cited, in accordance with accepted academic practice. No use, distribution or reproduction is permitted which does not comply with these terms. 